115 Erna, Rusnaini, \& Yudi: penguatan civic literacy dalam pebelajaran ...

\title{
PENGUATAN CIVIC LITERACY DALAM PEMBELAJARAN DEMOKRASI DAN PEMILU DAN IMPLIKAISNYA TERHADAP CIVIC ATITUDE MAHASISWA
}

\author{
Oleh : \\ Erna Yuliadari \\ Universitas Sebelas Maret Surakarta \\ e-mail: ernayuliandari@staff.uns.ac.id \\ Rusnaini \\ Universitas Sebelas Maret Surakarta \\ e-mail: rusnaini@staff.uns.ac.id \\ Yudi Ariana \\ Universitas Sebelas Maret Surakarta \\ e-mail: y_ariana@yahoo.com
}

\begin{abstract}
The level of literacy of the students in the subjects of democracy and elections are still low. Civic literacy became a prosecution along with the advances and advances in technology and the current globalization. This research aims to map out the civic literacy students, knowing the strategy of strengthening civic literacy in learning democracy and elections as well as to know the implications of the strengthening of civic literacy against civic atitude students. The methods used in this research in the form of qualitative descriptive. The data source used is the quisioner, interviews, observation, documents and studies supported by Focus Group Discussion (FGD). Location research in the civic education study programs Faculty of teacher training and the education. Research results showed civic literacy students relating to problems - problems or issues - issues in democracy and elections are lacking it is seen when a student performs an analysis of the outstanding issues and develop in the public good of the mass media both print and social media, students can not provide an analysis of those issues because the student is not at all know those issue
\end{abstract}

Keywords: civic literacy, democracy and elections, civic atitude 


\section{PENDAHULUAN}

Tingkat literacy mahasiswa dalam mata kuliah demokrasi dan pemilu masih rendah. Civic literacy menjadi sebuah tuntutan seiring dengan perkembangan dan kemajuan teknologi dan arus globalisasi. Civic literacy menjadi hal yang penting bagi warganegara, terutama mahasiswa karena penguasaan civic literacy akan membentuk menjadi warganegara yang baik (good citizen). Warga negara yang baik sangat diperlukan bagi kemajuan warganegara dalam kehidupan berbangsa dan bernegara. Oleh karena itu perlu dilakukan penguatan civic literacy. Era globalisasi membawa keadaan dunia semakin terbuka memberikan pengaruh negatif dan positif bagi karakter kebangsaan di Indonesia. Pengaruh negatif yang bagi generasi muda antara lain sudah mulai melupakan jati diri bangsa. Oleh karena itu perlu dilakukan penguatan civic literacy dalam pembelajaran demokrasi dan pemilu dikalangan mahasiswa.

\section{RUMUSAN MASALAH}

Permasalahan yang dikaji dalam penelitian ini adalah :

\section{Bagaimana Civic Literacy mahasiswa dalam pembelajaran demokrasi dan pemilu}

2. Bagaimana strategi penguatan civic literacy dalam pembelajaran demokrasi dan pemilu

3. Bagaimana implikasi penguatan civic literacy terhadap civic attitude mahasisawa

\section{METODE}

Metode yang digunakan dalam penelitian ini berupa kualitatif deskriptif. Sumber data yang digunakan adalah quisioner, wawancara, observasi, studi dokumen dan ditunjang dengan focus Group discussion (FGD). Lokasi penelitian di Program Studi Pendidikan Kewarganegaraan Fakultas keguruan dan Ilmu Pendidikan (FKIP) Universitas Sebelas Maret Surakarta (UNS) pada mata kuliah demokrasi dan pemilu.

\section{CIVIC LITERACY}

Civic literacy dimaknai sebagai kapasitas pengetahuan dan kemampuan warga negara untuk secara aktif berpartisipasi, dan civic litercay merupakan landasan bagi masyarakat demokratis. (Dwipayana, 2013) Menurut Suryadi (2010), di dalam civic literacy terdapat penguasaan bentuk pengetahuan politik warga negara yang nantinya akan diimplementasikan dalam bentuk - bentuk aktivitas kewarganegaraan. Civic literacy dimaknai sebagi kapasitas pengetahuan dan kemampuan warganegara untuk memahami dunia politik mereka, atau secara lebih luas diartikan sebagai kapasitas pengetahuan tentang bagaimana untuk secara aktif berpartisipasi dan memulai perubahan dalam komunitas dan masyarakat. Kemauan dan kemampuan untuk terlibat dalam discource publik hal ini sejalan 
dengan tujuan mata kuliah demokrasi dan pemilu untuk membentuk warganegara yang mengerti akan demokrasi dan menerapkan nilainilai demokrasi didalam kehidupan sehari-hari .

Dengan civic literacy dalam pembelajaran mata kuliah demokarsi dan pemilu diharapkan mahasiswa dapat membentuk jiwa kristis mahasiswa sebagai warganegara dalam menghadapi kehidupan sehari hari baik di dunia sosial maupun politik. pembelajaran politik di kelas dapat meningkatkan literasi politik atau civic literacy. Pembelajaran demokrasi dan pemilu yang dilakukan selama ini hanya dalam proses mendapatkan pengetahuan baru belum pada merekonstruksi isuisu sehingga mahasiswa menjadi aktif dan termotivasi

\section{Pembelajaran Demokrasi dan Pemilu}

Pembelajaran Demokrasi dan pemilu bukanlah sekedar proses mendapatkan pengetahuan baru, akan tetapi merekonstruksi skema - skema yang telah ada, di mana mahasiswa adalah peserta didik yang aktif dan termotivasi. Melalui tindakan mereka, mahasiswa menyusun skema - skema. Setiap skema dikoordinasikan dengan skema yang lain. Informasi yang baru diintegrasikan dan diinterelasikan dengan struktur pengetahuan yang telah ada dalam pikiran mahasiswa. Pembelajaran demokrasi dan pemilu diarahkan menjadi pembelajaran bermakna agar mahasiswa berpartisipasi penuh, punya kemampuan, bertanggungjawab dan mampu berpikir kritis terhadap persoalan -persoalan demokrasi dan pemilu. Pembelajaran demokrasi dan pemilu yang selama ini dilakukan hanya dalam proses mendapatkan pengetahuan baru belum pada merekonstruksi isu-isu sehingga mahasiswa menjadi aktif dan termotivasi. Sehingga perlu dilakukan perbaikan dalam RPS (Rencana Pembelajaran Semester) dan dikakukan pengembangan desain pembelajaran. Substansi materi perkuliahan demokrasi dan pemilu juga diarahkan kepada penguatan civic literacy mahasiswa yang nantinya dapat membentuk civic atitude dan kesadaran berdemokrasi.

PEMBAHASAN

\section{a. Pemetaan civic literacy dalam pembelajaran demokrasi dan pemilu}

Berdasarkan penelitian yang dilakukan peneliti menunjukan bahwa civic literacy mahasiswa terhadap isu - isu politik dan perempuan menunjukan bahwa 75 persen mahasiswa paham akan isuisu mengenai politik dan perempuan hal ini juga ditunjukan dengan respon mahasiswa yang positif terhadap keterwakilan perempuan dalam demokrasi. 


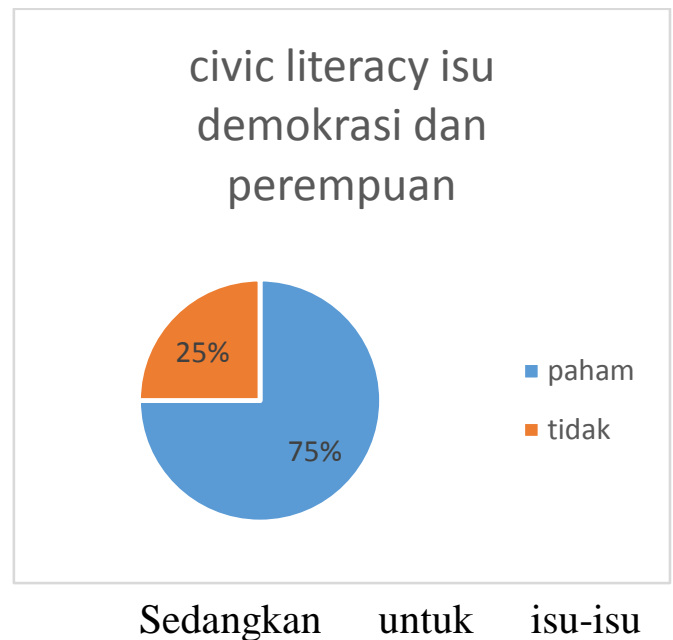

mengenai politik uang atau money politik semaua mahasiswa memahami dan mengetahui mengenai isu ini politik uang dalam pemilu hal ini ditunjukan dengan 100 persen mahasiswa paham akan hal tersebut

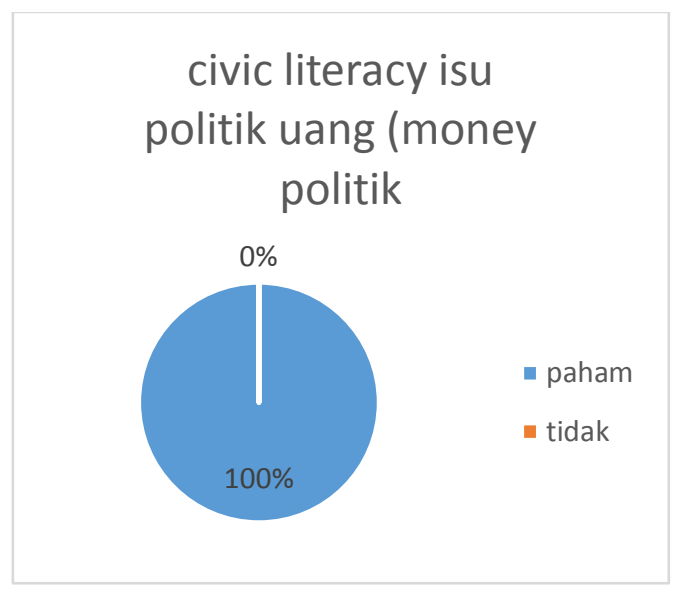

Sedangkan untuk civic literacy mahasiswa untuk isu mengenai politik Identitas dalam demokrasi dan pemilu
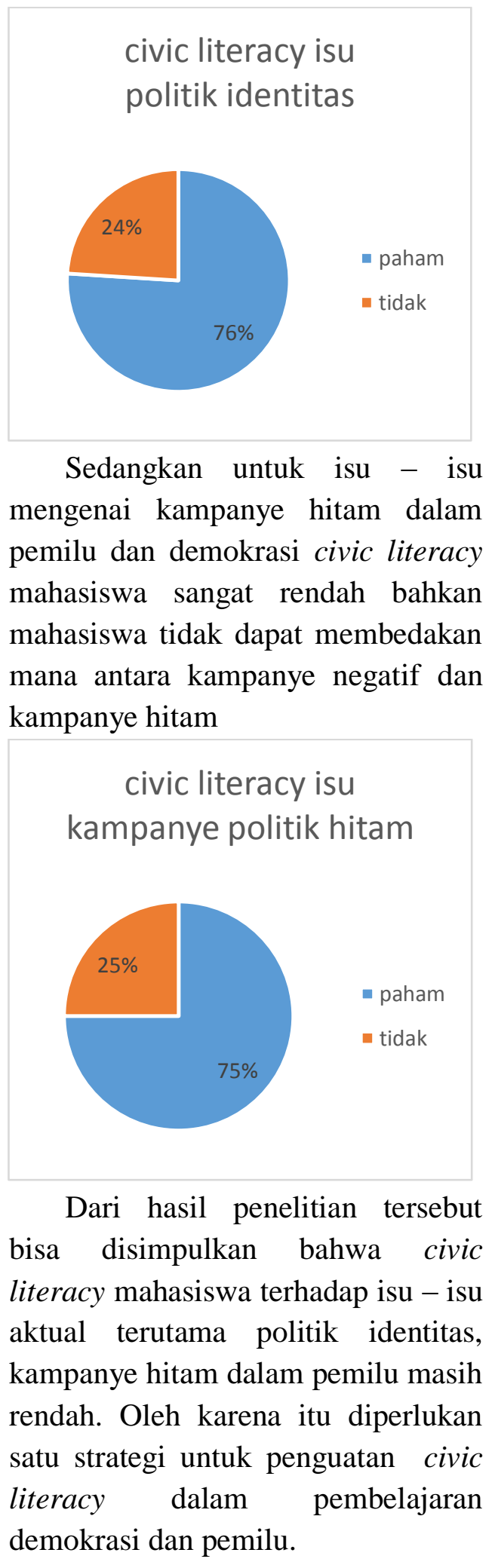


\section{b. Pengutan Pembelajaran} Demokrasi dan Pemilu melalui Isu-Isu Aktual

Pendekatan ini berangkat dari pemikiran bahwa pembelajaran demokrasi dan pemilu merupakan pembinaan warganegara dan berperan signifikan untuk meningkatkan civic literacy tentang demokrasi dan pemilu. Pendekatan dengan mengunakan isu - isu aktual dalam pembelajaran demokrasi dan pemilu menjadi strategis karena dalam hal ini pembelajaran demokrasi dan pemilu dapat menjadi wahana pembinaan warga negara agar memiliki civic attitude dan kesadaran akan nilai-nilai demokrasi. Penguatan civic literacy mahasiswa memerlukan dukungan semangat yang menjadi landasan utama untuk bangkit melawan berbagai tantangan yang sekarang ini menjadi realitas bangsa. Penguatan civic literacy tentang demokrasi dan pemilu penting agar mahasiswa mampu memahami perkembangan politik yang dihadapi bangsa dan negaranya.

Pembelajaran demokrasi dan pemilu berbasis isu-isu aktual sejalan dengan model pembelajaran konstruktivisme. Pengetahuan bukan merupakan fakta dari suatu kenyataan yang sedang dipelajari melainkan sebagai konstruksi kognitif seseorang terhadap obyek, pengalaman maupun lingkungannya. (Bambang Warsita,2008). Pembelajaran konstruktivisme menekankan pada pengetahuan secara bermakna agar mahasiswa dapat berpartisipasi penuh, berkemampuan dan komitmen yang bernalar terhadap demokrasi dan pemilu, pembelajaran mengikuti pandangan peserta didik dan menekankan pada proses serta aktivitas belajar dalam konteks nyata. Mata kuliah demokrasi dan pemilu merupakan mata kuliah yang diarahkan untuk menumbuhkan nilai - nilai dan kesadaran demokrasi. Sehingga dengan pembelajaran demokrasi dan pemilu akan timbul suatu kesadaran pada warga negara untuk menjadi warganegara yang baik yang memiliki kesadaran akan demokrasi.

\section{c. Implikasi Penguatan Civic Literacy Terhadap Civic Atitude Mahasiswa}

Civic literacy dalam pembelajaran demokrasi dan pemilu untuk memperkuat civic attitude mahasiswa, hal tersebut berfungsi untuk membentuk pola pikir dan tindakan untuk menjadi warga negara yang baik (good citizen) yang memiliki kecakapan civic attitude dan kesadaran akan berdemokrasi. Penguasaan kajian isu-isu tertentu membangun sikap kritis mahasiswa yang didasarkan pada pengetahuan akan demokrasi dan pemilu atau dikenal dengan kapasitas kemampuan civic literacy mereka untuk bersikap atau menentukan langkah nyata yang merupakan perwujudan civic attitude baik secara 
langsung atau tidak langsung yang akan mengarahkan mahasiswa untuk memiliki kesadaran berdemokrasi yang kuat. Hal ini dikarenakan isu yang berkembang dimasyarakat, terutama melalui media sosial dan perkembangan teknologi informasi sehingga banyak tersebar berita hoax, hate spech (ujaran kebencian) yang kebenarannya masih diragukan. Terhadap isu-isu tersebut tidak sedikit masyarakat yang langsung percaya dengan isu -isu yang tidak benar tersebut karena rendahnya civic literacy. Mahasiswa melalui pembelajaran demokrasi dan pemilu menunjukan respon positif yang mengarah pada kemampuan civic literacy setelah dilakukan pembelajaran dengan isu - isu aktual dibidang demokrasi dan pemilu . Hal ini ditunjukkan denagn berkembangnya daya pikir, dan sikap kritis mahasiswa dalam mengolah isu aktual mengenai demokrasi dan pemilu, kemudian melakukan analisis terkait isu-isu aktual tersebut dengan cara mencari sumber dan kebenaran isu-isu tersebut, kemudian bersikap sesuai dengan apa yang diyakini yang diimplepentasikan dalam civic attitude, sehingga mahasiswa memiliki kesadaran akan pentingnya berdemokrasi. Setelah melalui proses pembelajaran berbasis isu-isu aktual, mahasiswa menjadi kritis dalam menyampaikan analisis dan kesimpulan terhadap isu-isu yang demokrasi dan pemilu. Mahasiswa semakin kritis dan menimbulkan kesadaran akan pentingnya kesadaran berdemokrasi dengan keinginan untuk ikut memecahkan dan memberi solusi terhadap isu-isu aktual yang berkaitan dengan demokrasi dan pemilu sesuai dengan kapasitas pengetahuan yang mereka miliki melalui civic literacy.

\section{KESIMPULAN}

Civic literacy mahasiswa yang berkaitan dengan masalah masalah atau isu-isu dibidang demokrasi dan pemilu masih kurang hal ini terlihat ketika mahasiswa melakukan analisis terhadap isu-isu yang beredar dan berkembang di masyarakat baik dari media massa cetak maupun dari media sosial, mahasiswa tidak bisa memberikan analisis terhadap isu-isu tersebut karena mahasiswa sama sekali tidak mengetahui isu-isu tersebut. Penguatan civic literacy melalui strategi pembelajaran demokrasi dan pemilu berbasis isu-isu aktual dilakukan melalui proses pembelajaran yang struktur dan sistematis, dari proses identifikasi masalah pembelajaran, diskusi dan analisis sampai pada tahap evaluasi. Penguatan civic literacy dalam pembelajaran demokrasi dan pemilu melalui isu aktual dibidang demokrasi dan pemilu dapat meningkatkan penguasaan mahasiswa terhadap kajian isu-isu tertentu dalam demokrasi dan pemilu. Sehingga dapat membangun 
121 Erna, Rusnaini, \& Yudi: penguatan civic literacy dalam pebelajaran ...

sikap kritis mahasiswa yang didasarkan pada pengetahuan politik mereka atau civic literacy. Pembelajaran politik di kelas dapat meningkatkan literasi politik atau civic literacy mahasiswa 


\section{DAFTAR PUSTAKA}

Bambang Warsito.2011. Model Pembelajaran berbasis Masalah. Surabaya : Kementrian Pendidikan Nasional UNESA Pusat Sains dan Matematika Sekolah

Dwipayana,A.2013.” Civic Literacy” Naskah Combine , Maret 2013,Fisipol.

Robert . A Dahl. 2001. Perihal Demokrasi, Menjelajahi Teori dan praktik

Demokrasi Secara Singkat (on Democry).Terj. A. Rahman Zainudin.jakarta. Yayasan Obor

Suryadi,K,2010, “ Inovasi Nilai dan Fungsi Komunikasi partai Politik bagi Penguatan Civic Literacy "Naskah Pidato pengukuhan Jabatan guru Besar Ilmu Komunikasi Politik pada Fakultas Pendidikan Ilmu Pengetahuan Sosial, 24 November 2010. 